\title{
The Trend of Intelligent Education Under 5G Driven Artificial Intelligence
}

\author{
Wang Xiaoyu, Liu Chunyan \\ School of Computer Information and Science, Chongqing Normal University, Chongqing, China
}

\section{Email address:}

894243354@qq.com (Wang Xiao Yu), 804627889@qq.com (Liu Chun Yan)

\section{To cite this article:}

Wang Xiaoyu, Liu Chunyan. The Trend of Intelligent Education Under 5G Driven Artificial Intelligence. Science Innovation. Vol. 9, No. 3, 2021, pp. 86-91. doi: 10.11648/j.si.20210903.12

Received: March 2, 2021; Accepted: May 14, 2021; Published: May 24, 2021

\begin{abstract}
Under the background of actively advocating the development of educational informatization, the arrival of "5g + AI era" is leading the educational reform. In recent years, intelligence has become a new development trend in the education industry. The combination of new technologies such as voice recognition, image recognition, big data, artificial intelligence, virtual reality and the education industry has attracted much attention. As the main form of future education, intelligent education determines the development direction of future education and has a guiding role in future education. In this paper, under the background of educational informationization, the author first thinks about intelligent education, and then expounds how intelligent education can take the fast train of information technology reform in the environment of 5G technology and artificial intelligence. On this basis, how to explore the future education reform from the direction of intelligent education. Finally, from the two aspects of 5G information technology and artificial intelligence applied to intelligent education, the paper discusses the future trend of intelligent education and provides some reference for the development and research of intelligent education in the future.
\end{abstract}

Keywords: 5G, Artificial Intelligence, Education Informatization, Intelligent Education

\section{G驱动人工智能下智慧教育的趋势}

\section{王晓昱, 刘春燕}

重庆师范大学计算机与信息科学学院, 重庆, 中国

邮箱

894243354@qq.com（王晓昱），804627889@qq.com（刘春燕）

摘要：在国家积极倡导发展教育信息化的大背景下，“5G+ AI时代”的到来正在引领教育变革。近年来,智能化成为教育 行业的新发展趋势,语音识别、图像识别、大数据、人工智能、虚拟现实等新技术和教育行业的结合备受关注。智慧教 育作为未来教育的主要形态，决定了未来教育的发展方向，对未来教育有引导性的作用。该文首先在教育信息化的背 景下，对智慧教育进行了思考，其次阐明了智慧教育在 $5 \mathrm{G}$ 技术和人工智能的环境下如何搭乘信息技术变革的快车，在 此基础上, 如何从智慧教育的方向出发来探索未来教育的改革。最后综合考虑，从5G信息技术和人工智能应用于智慧 教育两个方面, 来论述智慧教育的未来趋势, 来为未来智慧教育的发展和研究提供一些参考。

关键词: $5 \mathrm{G}$, 人工智能, 教育信息化, 智慧教育 


\section{1. 引言}

第五代通讯技术标准简称为 $5 \mathrm{G}$, 其高效率、低延迟和 广覆盖的特点将会给生活带来颠覆传统的变化。5G通讯技 术将实现万物相互感应, 一切智能化的未来世界。首当其 冲的就是教育, 因为教育是国民素质的根本。中国《教育 信息化 2.0 行动计划》提出要推进智能教育, 开展以学习 者为中心的智能化教学支持环境建设, 推动人工智能在教 学、管理等方面的全流程应用等 $[1]$ 。随着人工智能高速发 展, 并且与教育的融合、应用已经有较多的产品, 人工智 能为未来智慧教育的环境营造和设备供需提供了底层的 技术, 让传统智慧教育改革有较强的可能性。将 $5 \mathrm{G}$ 通信技 术注入人工智能从而应用于教育领域, 促进教育的改革, 提供一种新的教育模式, 实现智慧教育的普及, 进而实现 教育信息化。

长期以来, “互联网+教育”的大潮一直浩浩荡荡, K12、 素质教育、职业教育等热点轮番上阵。5 $\mathrm{G}$ 赋予了教育行业 更多的想象，将进一步推动“AI+教育”的智慧教育时代到 来。据悉, 目前 $\mathrm{AI}$ 技术已经在组卷与批改、评测与智适应、 搜题与排课、AI教学与陪练等场景里初展身手, $5 \mathrm{G}$ 技术 加持则让人工智能应用场景再次深化, AI教室、AI教师等 也相继出现。

由此可见, 我们有必要讨论这两种新型的信息技术给 教育变革带来的影响, 为未来教育提供一种可行性的理论 支持。

\section{2. 新时代教育信息化环境下的智慧教育}

\section{1. 智慧教育引领新时代的教育}

智慧教育是指在“互联网+”、大数据、人工智能、虚 拟仿真等信息技术的支持下, 让学生能够主动学习、根据 自己的需要学习、按照适合自己的方式学习、找到适合自 己的学习环境学习、找到最适合自己的伙伴学习、得到最 适合自己的教师帮助学习, 逐步形成系统的思维能力和创 新性思维能力[2]。学生能够通过智慧教育系统掌握自己的 学习状态。教师对相应学生的变化实时作出相关的改变使 学生能够获得最有效的教师督导和知识学习的提升, 从而 达到最有效地学习活动[3]。

\section{2. 教育信息化促进智慧教育}

教育的核心是培养高素质人才。智慧教育作为教育现 代化的未来形态, 为办好更加公平更高质量的教育提供了 新的引擎[4]。“教育信息化”是着重利用最新的信息技术手 段来提升教育教学的效果, 其最终目标是提升教师教学质 量和学生的综合素质, 而不是单纯的去利用信息技术和学 习信息技术。

智慧教育的发展与实现离不了信息的支持, 从而需要 注入新的技术, 构建新型的教育模型。智慧教育的核心特 征就是学生智慧成长、教师智慧教、学生智慧学、管理者 智慧管、教师智慧成长、学校与家庭智慧沟通等 [5]。智慧 教育着重关注学生学习过程的优异程度和最终学生学习
的培养结果。具体而言就是从两方面来看智慧教育的实现 程度, 从学生来看, 学生能否利用智慧教育的学习平台找 到符合自己的学习方式, 达到理想的学习效果, 从教师来 看, 教师是否实时监测学生的学习活动, 并且及时的提供 相应的指导, 达到教师预想的学生掌握知识的程度。无论 是当前的教育模式还是教育的何种新模式, 其最终目标依 然是在当前社会的高速发展下, 提升人们解决当前社会出 现的相关领域实际问题的能力来适应当前社会的变化和 着重培养个人的创新能力等高纬度的能力培养。

\section{3. 智慧教育与教育信息化循环驱动加速教育现代化}

智慧教育作为教育信息化的未来形态, 教育信息化推 动智慧教育的发展。智慧教育的形式对未来教育改革作出 了指导方向, 为教育信息化发展指明道路。教育信息化作 为教育改革指导纲要为未来教育形式作出指示, 从而实现 教育现代化。教育现代化是中国教育改革的最终目标, 其 核心目的是实现人的现代化, 及教育主体的现代化。

教育信息化是将信息技术融入教育体系, 完善教育的 体系结构, 全面提升教育信息化, 为未来教育提供一种新 模式, 为构建全民学习环境提供理论支持。教育信息化的 发展必然引发新的教育模型, 从而实现教育改革的目的。 作为教育信息化的战略决策, 智慧教育从而应景而生, 智 慧教育是教育在信息时代的新模式, 是教育信息化推动改 革的新阶段和新成果。智慧教育能够构建全天候、全地域 的学习型社会, 从而建成服务全民终身学习的现代教育体 系。

\section{5G技术的发展应用赋予智慧教育机遇与保障}

\section{1. $5 \mathrm{G}$ 的问世创造万物智能的世界}

现代社会上网的网民都知道的一句非常有名的话, “4G 改变生活, 5G改变社会”。在英国召开的第九届全球移动宽 带论坛会上, 华为轮值董事长胡厚芘就提出了在未来 $5 \mathrm{G}$ 支 持的社会下构建“万物互联互通的智能世界”。也就是说在 $4 \mathrm{G}$ 通信技术改变了我们生活方式, 那5 G 将会重新构造整个 社会, 将会营造一种颠覆传统的未来智能世界。随着 $5 \mathrm{G}$ 通 信技术的发展与应用, 将会给社会带来较大而影响。2019 年 11 月山西省举行了 $5 \mathrm{G}$ 远程医疗启动会, 会议现场, 一台 高端人工晶状体植入手术示教大片, 被实时传送到1300公 里外的成都医药大学附属银海眼科医院、300公里外的运城 眼科医院和长治市人民医院学习交流。山西电信总经理靳 建勇表示5G通信技术将会给社会带来变革, 电信将充分发 挥 $5 \mathrm{G}$ 的高速率、低延迟和广覆盖的特征优势, 探索 $5 \mathrm{G}$ 技术 在更多领域的更高价值和更多应用。5G技术的融合将会促 进更多的领域发展, 包括智能机器人、智慧城市、智能家 居、智慧校园、智慧家庭、远程协作、云端服务等。

\subsection{G通信技术赋能智慧教育新可能}

从 $4 \mathrm{G}$ 到 $5 \mathrm{G}$ 信息技术的转变, $5 \mathrm{G}$ 的传输速率已经远远 高于 $4 \mathrm{G}$, 这就会给未来信息传输提供一个很高的传输效率, 并且不会出现有卡顿的情况。把 $5 \mathrm{G}$ 的高传输速率特征嫁接 
给智慧教育, 从而建立智慧教育学习平台, 在学生依靠学 习平台, $5 \mathrm{G}$ 高速率传输的支持下, 真正实现学生的智慧学 与教师的智慧教。在智慧学习平台上共同分享优质课程资 源, 学生能够及时地下载并且学习, 优秀教师在智慧学习 平台上开通远程优质课程, 学生可以在线观看。学生根据 自己的情况以及能力找到合适的课程与学习环境, 教师根 据同步输出的学生学习反馈, 给予学生有效的指导, 帮助 学生实现个性化学习。在 $5 \mathrm{G}$ 信息技术的支持下, 打造大范 围的学习平台, 能够让偏远地带的学生也能像沿海地区的 学生一样接受高素质的教师资源与学习环境。学生智慧学 跟教师智慧教在 $5 \mathrm{G}$ 支持下同步结合, 真正实现智慧教育倡 导的公平学习和全民学习。

$5 \mathrm{G}$ 是当前已经开始应用的最低延迟的通信技术, 接近 毫秒的低延迟可以为数据同步提供可靠地优势。5G通讯技 术的低延迟功能使得远程人机协同、人人协作和智能操控 等可以 实现精确同步、精准协同、精准定位以及视频“同 步传输” $[6]$ 。从 $5 \mathrm{G}$ 通信技术的低延迟功能为智慧教育的同 步传输打下坚实的基础, 学生可以同步优秀教师的优质学 习资源, 教师可以同步学生课程内容学习的反馈, 学生和 教师双方同时同步了解, 让国内的教育实现一个层次的改 革, 从 $5 \mathrm{G}$ 通信技术的特征点植入智慧教育, 从智慧教育的 普及推进教育信息化，从教育信息化的方向改革中国教育。

$5 \mathrm{G}$ 通讯技术采用密集基站的结构布局,消除了同一时 段大频率传输数据信号不稳定的情况。这种广覆盖的结构 布局使得信号在基站之间传输有可靠稳定的性能, 并且结 合 $5 \mathrm{G}$ 高传输效率, 使得信息数据在低延迟的情况下快速传 播, 实现物与物之间关联, 最终实现智慧世界的构建。广
覆盖的特性正好对应智慧教育的需求, 智慧教育需要构建 的是全民全地域全天候的学习环境。密集的基站布局可以 使每个基站的范围内创建智慧教育平台, 把智慧教育平台 中的资源接入到基站的信号传输中，从一个基站到另一个 基站的传输中, 智慧教育的资源将得到大范围的传播, 人 们只要在有信号的地方就可以随时随地的对智慧教育平 台中的资源进行学习, 实现只要有信号的地方就有学习资 源, 利用智慧教育真正实现新时代全民学习的智慧型社会。

\subsection{G技术下智慧教育的模型构建}

$5 \mathrm{G}$ 通信技术加持的智慧教育的核心要素是将学习资 源共享化, 达到全民学习的目的。通过 $5 \mathrm{G}$ 通信服务中心进 行存储和处理学习资源, 通过家庭、学校和图书馆等外围 智慧教育学习个体的信息输入与输出, 学习资源进入智慧 教育平台, 学生通过智慧教育平台的共享性可以按需查看 相关的课程资源, 通过智慧教育平台的互联性, 将大量的 学习资源通过基站相互传输, 基站之间的信号传输利用 $5 \mathrm{G}$ 的传输规则进行相互之间的传导, 再将各个基站的学习资 源传输进入通信服务中心，通信服务中心在处理信息资源 的同时将返回的教学资源一同打包重新返回给基站, 利用 基站之间的信号传输将学习资源隔离、整合以及同化返回 给智慧教育平台, 学习者在通过智慧教育平台的网络环境 进行学习。从中心到外围端点的信号传输分享, 再从外围 端点传输学习资源到中心处理器, 无限的循环更替将达成 所有学习资源的共享。其模型图如图1所示:

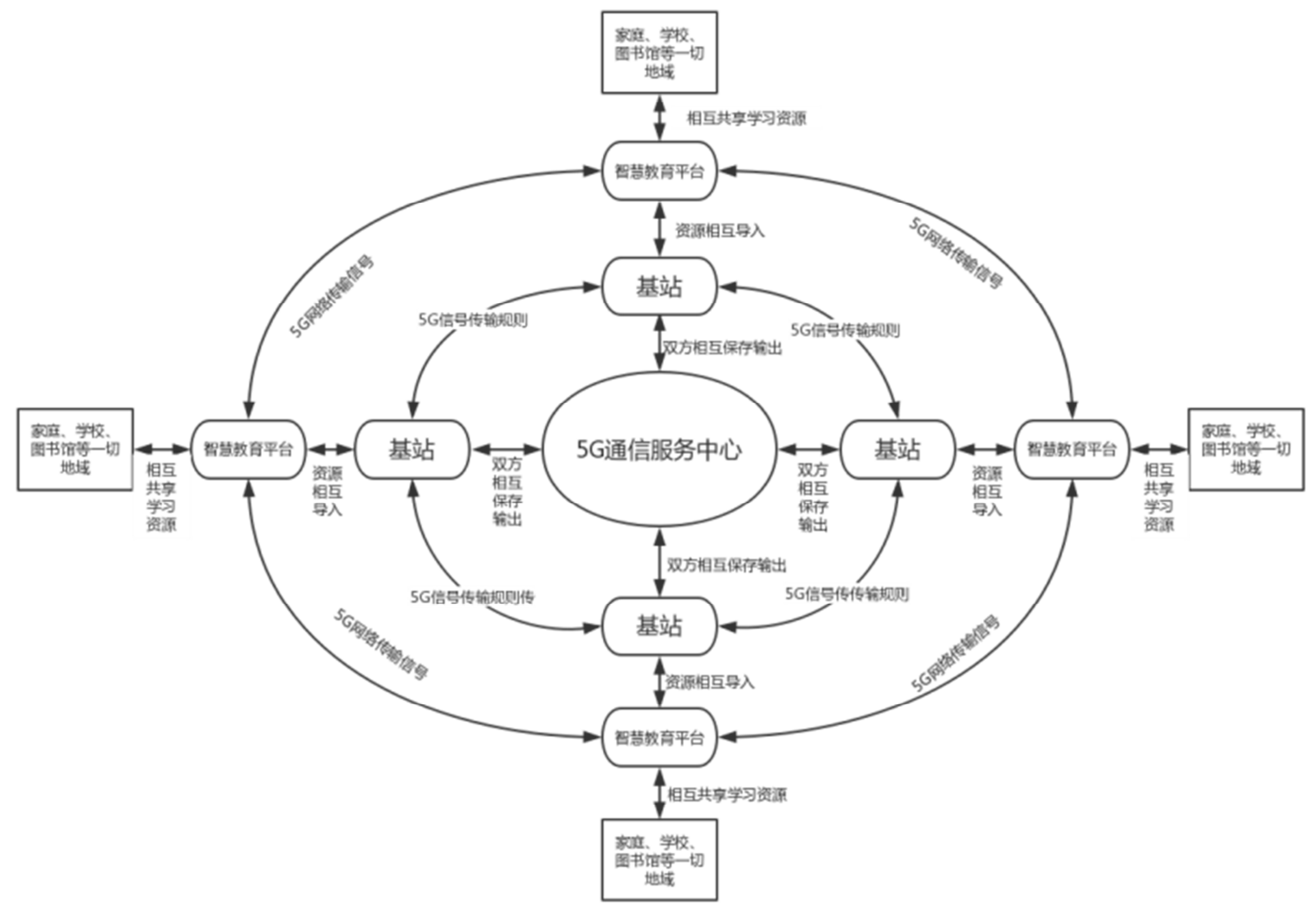

图15G通信技术支持下的智慧教育模型。 
通过这种模型的构建, 学习资源的无限循环和分享利 用, 将会解决当前智慧教育的学习资源缺乏的问题。多节 点分享课程的框架模型实现了学习资源的优化与整合。基 于 $5 \mathrm{G}$ 通信技术的高传输率、低延迟和广覆盖的特性, 充分 调动和利用不同地区、不同类型和不同节点的课程资源的 教与学, 构建多元化的模式进一步加速智慧教育的开发与 应用。智慧教育平台的建立与通过基站互联互通的学习模 型, 学习者通过智慧教育平台就可以直接教与学, 学习者 不再深入讨论关于信息技术的问题, 大大的降低了学习者 繁琐的学习步骤。但是智慧教育平台的构建与研发需要跨 界完成, 通过政府主导, 并邀请当前平台所涉及领域的研 发团队来完成整个平台的开发与构建, 让学习者始终只需 要考虑学习这一简单步骤就可以, 避免过多的步骤造成的 学习阻碍。以第五代通信技术构建的智慧教育将给教育带 来巨大的影响, 将会进一步消除传统模式的教学影响, 能 够实现跨区域、跨时段的远程学习。5G支持下的智慧教育, 必须要构建新的教学模式和教学策略, 充分发挥 $5 \mathrm{G}$ 的优势, 以形成 $5 \mathrm{G}$ 通信技术下即用即学的学习模型。

\section{4. 人工智能技术的活跃为智慧教育创设了新的 环境}

\section{1. 人工智能将会彻底将教育智能化}

人工智能技术正在慢慢地渗透进人们的生活、工作、 学习等方面, “教育十科技”和“互联网+教育”将不再是人们 的想法, 而是现在正在进行的教育革命。在 2019 年5月 16 日-18日, “2019国际人工智能与教育大会”在北京隆重召开, 会议主题为“规划人工智能时代的教育: 引领与跨越”[7]。 正如中国国务院副总理孙春兰所说, 推动人工智能和教育 的融合, 是各国面临的共同机遇和挑战[8], 努力实现规模 化教育和个性化培养的有机结合, 不断提升各类人才的创 新精神和实践能力, 与各国共享智能教育的成果。

面向人工智能的时代, 中国教育紧跟技术的变化, 相 继发布《教育信息化十年发展规划（2011-2020年）》和 《教育信息化 2.0 行动计划》[9]。中国人民大学附属中学 校长翟小宁表示, 未来的教育方式将以人工智能和大数据 为支撑, 学生自主学习为主、教师个性化指导为辅, 以“师 生学习共同体”的形态呈现 [10]。智慧教育作为未来教育和 人工智能相互融合的教学模式[11], 将会给教育带来颠覆 性的革命。

\section{2. 人工智能将催化深度智慧教育}

当前, 随着人工智能技术趋向于成熟的阶段, 不仅推 动了以“数据技术”为核心的智慧校园的建设, 更使学校的 整体管理架构发生了转变, 使学校的教学活动和管理模式 更加趋向与自动化。以人工智能引导的新的教学模式与传 统的教学模式将会有很大的改观, 由此可知人工智能为代 表的新一代信息技术, 正大动力的推动教育形态走向智慧 化，形成人工智能时代新型的智慧教育。

人工智能时代的智慧教育重要目标是培养“智慧人 才”。着重培养人工智能时代的创新创造人才、发展能够
适应社会岗位需求的终身学习者。利用人工智能工具, 配 合智慧教育平台进行社会化的生产, 不断利用智慧教育的 教育资源, 以无缝式凡在学习方式进行学习。构建人工智 能时代新型智慧教育, 推动我国教育信息化, 实现教育现 代化, 从而对我国整体教育体系进行改革, 并逐渐确定新 型智慧教育的制度体系。

\section{3. 人工智能引导智慧教育的模型构建}

人工智能支持的智慧教育是将教育资源整合, 将教育 资源整合成信息数据, 通过人工智能处理系统实时处理和 反馈学习资源, 将教育资源形成大数据, 利用人工智能技 术进行分析, 实时观察、采集和反馈课堂教学和学生行为, 从而实施精准教学, 以便适应每个学生个体的学习特征, 促进学生的个性化发展。教师制定整个课堂的教学, 通过 教师的执行, 对课堂形成一种过程。教师通过整个课堂的 教学氛围将自己的不足及时反馈, 人工智能处理系统通过 全程采集课程的信息数据, 将其录入系统中并且经过一定 的处理之后再反馈给教师, 教师在课下通过对人工智能处 理系统反馈来改进自己的教学过程, 再录入人工智能系统, 人工智能系统再将教师更正过后的教学过程和教学资源 及时的录入到教学环境中, 从而形成一种循环, 达到教学 过程最优化和教学资源最大的利用程度[12]。从学生而言 通过选择自己合适的教学过程和教学资源来进行学习, 在 学习完相应的课程之后, 教学过程形成当前学习者的数据 资源反馈给学生, 学生利用反馈的信息及时的查漏补缺, 人工智能系统将记录的学生学习过程形成数据进行采集 和保存, 然后反馈给老师, 老师及时的指导之后再将学生 的不足反馈给学生个体从而学生知道哪些地方的不足之 后, 学生通过课程教学系统自主学习, 以达到学生得到及 时的学习指导, 力求课程学习资源的最大利用率。其结构 模型如图2所示:

通过这种模型的建立, 在人工智能、大数据等技术的 支持下, 针对教育改革, 探索智慧教育新型模式, 通过探 索总结教育的新思路和新方法, 再根据思路和方法, 通过 技术的支撑和构建来实施新的教育结构和教育体系。在智 慧教育视域下, 能够对教育教学全过程进行实时监测与 调控, 最大限度地将师资、设施设备、场地等教育资源合 理、均衡配置; 能够将优秀教师的教学智慧和典型学生的 学习经验实时提供给每一个学生和教师, 改变优质教育智 慧的供给形态等[13]。通过该模型的构建将学生和教师的 所有教与学过程记录成数据, 并进行处理和反馈, 学生和 教师通过反馈的信息及时的更正, 可以将学习资源同步更 新和输入输出, 将智慧教育推向了更加智能的阶段。

\section{5. 结语}

在当前信息爆炸的时代, 如何形成全民学习和如何打 造终身学习平台是各国政府都应该重视的领域。智慧教育 的实现离不开信息技术的支撑, 实际上, 教育的本质是一 种特殊的服务,信息技术的进步为教育服务的智慧化水平 创造了条件[14]。教育最终是培养新时代需要的人才, 培 养能够解决社会发展中出现的问题的高素质人才。 


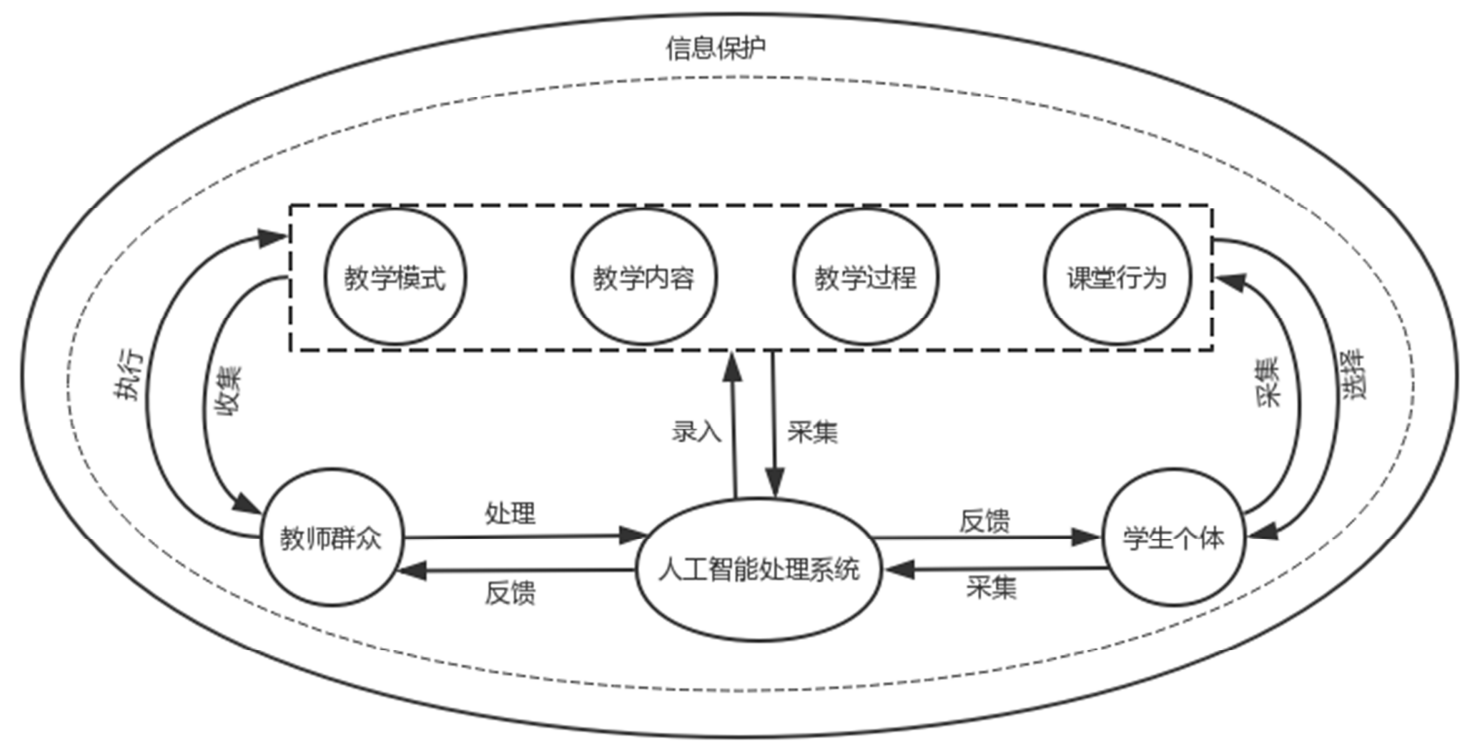

图2 人工智能环境中智慧教育的模型。

$5 \mathrm{G}$ 通信技术的问世给予了人们共同学习的信息技术 条件, 人工智能的应用为人们解决问题提供了一种新的方 法和途径。将 $5 \mathrm{G}$ 通信技术植入人工智能中, 造就更加智能 的社会。在中国教育信息化规划的提出之后, 利用 $5 \mathrm{G}$ 通信 技术和人工智能技术造就新一代的智慧教育从而形成新 时代的教育体系, 为未来教育现代化的实现提供一种技术 和理论上面的支持，从而加速教育现代化的前进步伐。

$5 \mathrm{G}$ 联合人工智能已成为新一代的智慧教育的核心技 术支撑。新时代的智慧教育将颠覆传统教育, 改变传统教 育的结构和教育体系, 架构新时代智慧教育的教育体系是 当前中国教育领域急切需要解决的问题, 从重新构建教育 结构来促进教育改革的目的 $[15]$ 。5G通信技术和人工智能 的融合为教育做好了一定的底层结构, 两者的深度融合为 智慧教育更加智能化做好了铺垫。新时代智慧教育的构建 的教育体系将成为未来教育的标志。5G通信技术和人工智 能赋能的智慧教育构建步伐的加快, 进而加快教育改革的 步伐, 从而达到教育信息化的要求, 进而实现教育现代化。

新时代的智慧教育将是面向全社会不同领域、不同个 体的。智慧教育最终的目的是构建全民无地域差、全天候 实时学习的学习型社会。社会公众将通过智慧教育平台构 建自己的学习体系, 形成针对自身价值提高的知识领域, 通过对专业领域知识的构建来提高自身的整体素质, 形成 对新时代社会有贡献的高素质人才。

\section{致谢}

本文受重庆市研究生教育教学改革研究项目: “双一 流, 背景下地方高校硕士研究生生源状况调查与对策研究” （项目编号：yjg193095）资助。

本文受重庆市教育科学“十三五”规划（重点）项目“基 于AHP的重点学科建设质量评价指标体系研究一以重 庆市高校为例”（项目编号：2017-GX-114）资助。
本文受重庆市研究生教育教学改革研究项目 (重大项 目) “大数据背景下基于SEM的研究生科研绩效评价研究 ——重庆市高校为例”（编号：yjg181008）资助。

本文受教育部人文社会科学研究2018年度规划基金 项目“双一流”视野下教师教育学科群及评价体系研究”

(项目编号: 18YJA880061) 资助。

本文受重庆师范大学研究生项目: “基于CIPP模式的 研究生创新创业教育评价研究” (项目编号: 19TW2XY04) 资助。

本文受重庆师范大学研究生项目: “大数据视野下的 研究生在线教学质量评价研究一以重庆师范大学为例” （项目编号：YKC20046）资助。

本文受重庆师范大学研究生项目: “教师教育学科群 特征及优化策略研究一以师范院校为例” (项目编号: YKC20047）资助。

本文受重庆师范大学研究生项目: “教师教育学科群 维度体系构建实证研究”（项目编号：YKC20045）资助。

\section{参考文献}

[1] 教育部关于印发《教育信息化 2.0 行动计划》的通知[EB/OL]. http://www.moe.gov.cn/srcsite/A16/s3342/201804/t20180425 334188.html,2018-04-18.

[2] 钟绍春 唐烨伟 王春晖. 智慧教育的关键问题思考及建议 [J]. 中国电化教育, 2018(1):7-7.

[3] 赵淋淋. 我国智慧教育研究的可视化研究分析 [J]. 软件导 刊(教育技术), 2019(05):8-11.

[4] 马小强施建国 程莉莉 王珠珠. 智慧教育的发展及价值 取向分析[J]. 中国电化教育, 2017(12):6-6. 
[5] 钟绍春. 构建信息时代教育新模式 $[\mathrm{J}]$. 电化教育研究, 2019(04):24-30.

[6] 吕梦嘉 张环 张晓虹. 电子书包环境下初中化学《水的组 成》智慧教学案例研究 $[\mathrm{J}]$. 中国信息技术教育, 2019(01):55-58.

[7] 泽恩. “人工智能教育”变革任重道远 $[\mathrm{J}]$. 上海企业, 2019(06):54-55.

[8] 徐靖程. 国际人工智能与教育大会在北京成功召开 $[\mathrm{J}]$. 中 小学信息技术教育, 2019(06):6-6.

[9] 钟绍春 唐烨伟. 人工智能时代教育创新发展的方向与路 径研究 [J]. 电化教育研究, 2018(10):7-7.

[10] 刘石磊. 人工智能掀起 “智慧革命”[J]. 科技传播, 2018(07):2-2.
[11] 钟绍春. 大数据驱动教学变革与创新 $[\mathrm{J}]$. 中小学数字化教 学, 2019(05):7-10.

[12] 于巧娥 王林毅. “互联网十”视野下高校智慧校园创新应用 模式研究[J]. 学理论, 2018(4):2-2.

[13] 邹嫱. 关于智慧教育的若干问题的思考及建议 [J]. 科技资 讯, 2018(23):165-165.

[14] 袁文光 田娜. 大数据背景下的智慧学习研究 [J]. 青岛大学 学报(自然科学版), 2018(S1):43-45

[15] 曾祥跃. 一流大学继续教育的战略定位与布局 $[\mathrm{J}]$. 成人教 育, 2019(07):17-22. 